\title{
Antibacterial Effect of Crab Shell Extract on Klebsiella pneumoniae and Proteus mirabilis
}

\author{
Tracy Adole ${ }^{1}$ and Barry A. Omogbai ${ }^{2}$ \\ ${ }^{1}$ Uptonville Oil and Gas Institute, 129/133 Woji Road, GRA Phase 2, Port Harcourt, Rivers State, Nigeria. \\ ${ }^{2}$ Department of Microbiology, Faculty of Life Sciences, University of Benin, Benin City, Nigeria.
}

ABSTRACT : The objective of this study was to examine the antibacterial effect of crab shell extract on Klebsiella pneumoniae and Proteus mirabilis. K. pneumoniae and P. mirabilis were isolated from urine and wound specimen and characterized using standard laboratory methods. Antibacterial susceptibility testing using crab shell extract showed that only K. pneumoniae were sensitive while P. mirabilis were resistant. Isolates of K. pneumoniae had varied minimal inhibitory concentration, with isolates Kpl and Kp3 having $12.5 \mu \mathrm{g} / \mathrm{ml}$ while isolates $\mathrm{Kp} 2 \mathrm{had} 6.25 \mu \mathrm{g} / \mathrm{ml}$. At a concentration of $200 \mu \mathrm{g} / \mathrm{ml}$ of crab shell extract, the highest zone of inhibition of K. pneumoniae was $12 \mathrm{~mm}$. This figure is however low when compared with commonly used antibiotics which gave larger zones of inhibition at lower concentration.

Keywords - K. pneumonia, P. mirabilis, chitin, Chitosan, cellulose.

\section{INTRODUCTION}

Crab shell is made up of three basic components. These are; chitin, protein and calcium salts of which chitin is most important for scientific studies [9]. Chitin is a fairly completely acetylated polysaccharide in nature, being only second after cellulose [12]. It can be also be found in other animals [exoskeleton of crustacean and insects] as well as in fungi, mushrooms and yeast [2; 12].

\subsection{History/ Back ground of Chitin}

Chitin was first isolated by Professor Henri Bracomot, Director of the Botanical Garden in Nancy, France from the cell wall of mushrooms in 1811. It was known then as fungine. In 1823, Odier renamed fungine as chitin [meaning tunic in Greek] almost three decades before the isolation of cellulose [20].

\subsection{Chemistry of Chitin}

Chitin is a white and porous polysaccharide. It is a biopolymer composed of N-acetyl-Dglucosamine, a chemical structure very close to cellulose except that the hydroxyl group in $\left[\mathrm{C}_{2}\right]$ of cellulose is being replaced by the acetamide group in chitin [20].

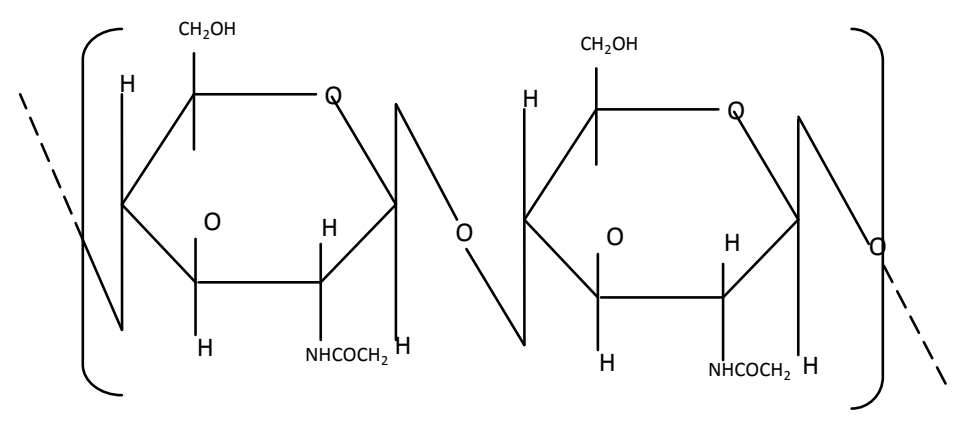

Figure 1: Structure of Chitin 


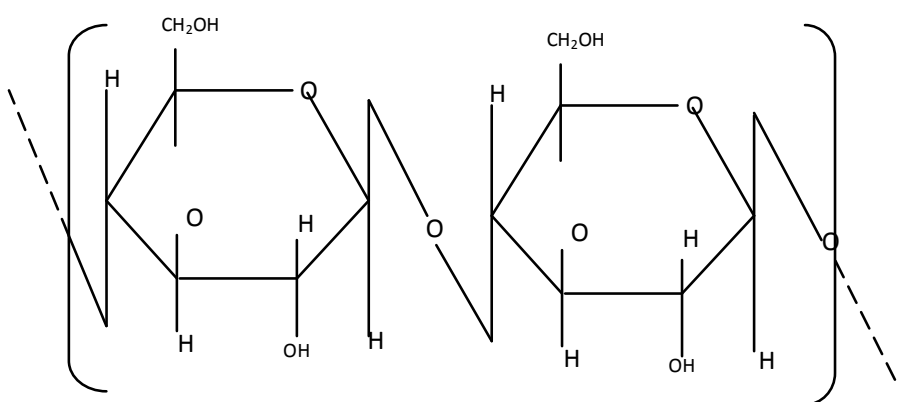

Figure 2: Structure of Cellulose

It's unit are joined by -1.4 links and chains are arranged anti-parallel which combine into a highly crystalline structure, within which the sugar residue are heavily H-branded making the chains very stiff and stable [23].

The deacetylation of Chitin produces a non-toxic biodegradable polymer of D-glucosamine known as Chitosan. It is of high molecular weight and also very similar to cellulose [20].

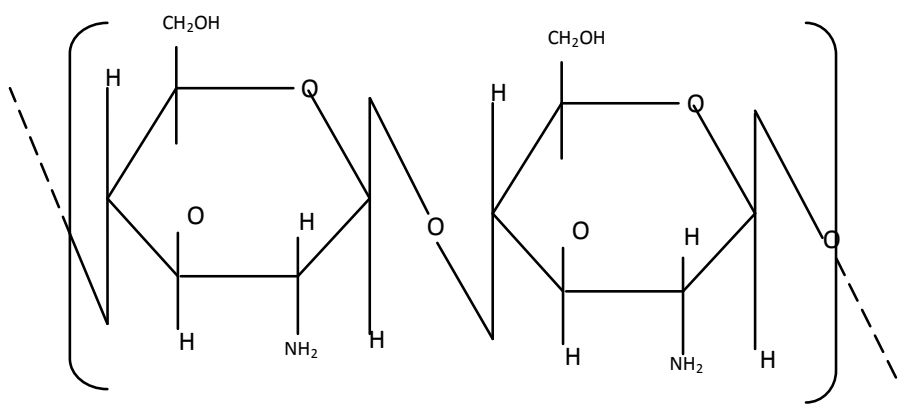

Figure 3: Structure of Chitosan

Chitosan is the important derivative from crab shell extract known to have been used for several application, including domestic, agriculture and biopharmaceutical [8].

\subsection{Application of Chitosan}

Application of chitosan can be classified mainly into three categories according to the requirements on the purity of the chitosan [8]. These are;

\subsubsection{Technical grade for the agricultural and waste management treatment:}

Chitosan has been used for seed coating, frost protection, bloom and fruit setting stimulation and protective coating for fruits and vegetables. This is because it triggers the defensive mechanism in plants and also stimulates growth [8]. It is also a known flocculating agent which is biodegradable and of natural origin hence being used to improve the effectiveness of water treatment [20].

\subsubsection{Pure grade for food and cosmetics industries:}

Chitosan is also being used as food ingredient in Japan, Europe and USA. It is not digested by the human body, thereby acting as a fibre with the ability to reduce $20-30 \%$ the amount of cholesterol absorbed by the human body $[21 ; 13 ; 14]$. Also as an antimicrobial agent, it is sprayed in dilute forms on foods and fruits [20].

\subsubsection{Ultra-pure grade for biopharmaceutical uses:}

In this field, many properties of chitosan is employed, these are; bacterostatic, immunologic, antitumor, cicatrizant, haemostatic and anticoagulant properties [1]. For example, due to its cicatrizant properties it has been used as a component in all types of dressing, surgical sutures, dental implants and in rebuilding bones and gums [15]. Chitosan is also helpful in kidney failure as it binds with toxins in the digestive tract thereby leading to their excretion [11]. 
Several research have been carried out to assess the antimicrobial activity of crab shell extract on various microbes but none has been done to assess its effect on Klebsiella pneumonia and Proteus mirabilis which are common causes of urinary tract and nosocomial infections [6; 22]. In addition, the Nigeria government has not paid attention to the effect usage of crab shell. Therefore, this study not only aims to fill that void in literature by examining the antimicrobial activity of crab shell extract on both K. pneumonia and $P$. mirabilis, but also to highlight the economic importance crab shell can bring to the government of Nigeria.

\section{RESULTS AND DISCUSSION}

The antimicrobial activity of crab shell extract is presented in Table 1. From the table the average minimum inhibitory concentration [MIC] of Klebsiella pneumoniae [Kp] was determined to be $10.42 \mu \mathrm{g} / \mathrm{ml}$. Table 2 shows the activity of the $1 \%$ acetic acid used.

Table 1: Activity of crab shell extract on clinical isolates

\begin{tabular}{|c|c|c|c|c|c|}
\hline \multirow[t]{2}{*}{ Concentration $[\mu \mathrm{g} / \mathrm{ml}]$} & \multicolumn{5}{|c|}{$\begin{array}{l}\text { Zone of inhibition [mm] } \\
\text { Clinical Isolates }\end{array}$} \\
\hline & Kp1 & Kp2 & Kp3 & Pm1 & $\mathrm{Pm} 2$ \\
\hline 100.000 & 8 & 10 & 9 & 0 & 0 \\
\hline 25.000 & 6 & 7 & 6 & 0 & 0 \\
\hline 12.500 & 2 & 3 & 2 & 0 & 0 \\
\hline 3.125 & 0 & 0 & 0 & 0 & 0 \\
\hline 1.560 & 0 & 0 & 0 & 0 & 0 \\
\hline
\end{tabular}

Table 2: Activity of acetic acid on clinical isolates

\begin{tabular}{llllll}
\hline & \multicolumn{2}{l}{ Zone of inhibition $[\mathrm{mm}]$} & & \\
Concentration [\%] & \multicolumn{2}{l}{ Clinical Isolates } & & Pm1 \\
\hline & Kp1 & Kp2 & Kp3 & 0 & 0 \\
0.500 & 1 & 2 & 2 & 0 & 0 \\
0.250 & 0 & 0 & 0 & 0 & 0 \\
0.125 & 0 & 0 & 0 & 0 & 0 \\
\hline
\end{tabular}

Activities of known concentrates of antibiotics on clinical isolates are shown in Table 3.

Table 3: Activities of antibiotics on clinical isolates Zone of inhibition [mm]

\begin{tabular}{|c|c|c|c|c|c|c|}
\hline \multicolumn{2}{|c|}{ Antibiotic disc content $[\mu \mathrm{g}]$} & \multicolumn{5}{|c|}{$\begin{array}{l}\text { Zone of inhibition [mm] } \\
\text { Clinical Isolates }\end{array}$} \\
\hline & & Kp1 & Kp2 & Kp3 & Pm1 & Pm2 \\
\hline Ciprofloxacin & 10 & 26 & 27 & 30 & 30 & 30 \\
\hline Amoxicillin & 30 & 20 & 22 & 21 & 30 & 30 \\
\hline Augmentin & 10 & 14 & 15 & 14 & 16 & 17 \\
\hline Gentamycin & 30 & 10 & 11 & 10 & 30 & 30 \\
\hline Pefloxacin & 30 & 30 & 30 & 30 & 30 & 30 \\
\hline Tarvid & 10 & 30 & 30 & 30 & 30 & 30 \\
\hline Streptomycin & 30 & 10 & 12 & 11 & 12 & 11 \\
\hline Septrin & 30 & 12 & 13 & 12 & 12 & 12 \\
\hline Chloramphenicol & 130 & 10 & 11 & 11 & 10 & 10 \\
\hline Sparfloxacin & 10 & 14 & 15 & 15 & 16 & 15 \\
\hline
\end{tabular}

It was observed from result that the three isolates of Klebsiella pneumoniae were sensitive to the crab shell extract, demonstrating the fact that the extract had antibacterial potential. Also observed is the increase in the susceptibility pattern with increase in concentration on of the extract [see table 1]. The highest zone of inhibition [12mm] was recorded for isolate $\mathrm{Kp} 2$ at $200 \mu \mathrm{g} / \mathrm{ml}$. This figure is however low when compared to zones of inhibition of commonly used antibiotics, when isolates of $K$. pneumoniae were subjected to them [see table 3].

Results showed that Proteus mirabilis were resistant to crab shell extract and susceptible to commonly used antibiotics [see table 3]. 
Results also showed that the acetic acid used as a carrier of the crab shell extract contributed insignificantly to the antimicrobial property of the crab shell extract [see table 2].

\subsection{Source of crab}

\section{EXPERIMENTAL SECTION}

Sixty crabs were obtained from Benin city and then killed mechanically with their shells emptied of all tissue. Shells were then washed with distilled water, oven dried for 7 hours, thereafter ground into fine powder.

\subsection{Preparation of crab shell extract}

Preparation of crab shell extract consist of four fundamental steps: deproteinization, demineralization, decolouration and deacetylation [see figure 4]. All chemicals used during each steps were decanted and powder washed with distilled water before the next stage. $200 \mathrm{ml}$ of $3.5 \% \mathrm{NaOH}$ was used to deproteinize $20 \mathrm{~g}$ of fine powder of crab shell in a beaker at a temperature of $65^{\circ} \mathrm{C}$ for 2 hours. The shells were then demineralised by adding $200 \mathrm{ml}$ of $1 \mathrm{~N} \mathrm{HCL}$ into the beaker an left for 30 mins at room temperature. Decolouration was carried out by adding $200 \mathrm{ml}$ of $0.315 \% \mathrm{NaOCL}$ for 5 mins at room temperature. Finally, $200 \mathrm{ml}$ of $50 \% \mathrm{NaOH}$ was used for deacetylation for $15 \mathrm{mins}$ at $121^{\circ} \mathrm{C}$. After thorough washing of the powder, it was then oven dried and $\mathrm{pH}$ determined and found to be 5.0. $2 \mathrm{~g}$ of extract was dissolved in $10 \mathrm{ml}$ of $1 \%$ acetic acid and then serially diluted into test tubes using the double fold dilution method adapted from [10] to get different concentrations/dilutions of extract.

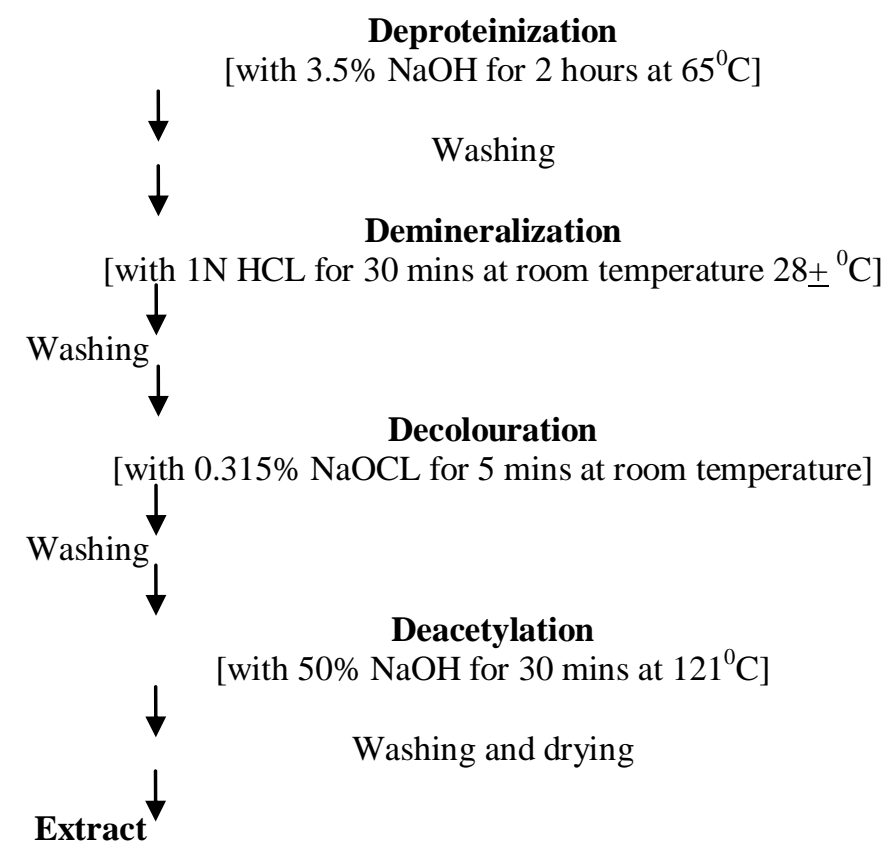

Figure 4: Flow chart of preparation of crab shell extract

\subsection{Source of Microorganisms}

Three isolates of Klebsiella pneumoniae $[\mathrm{Kp}]$ and two isolates of Proteus mirabilis $[\mathrm{Pm}]$ were obtained from patients with wound and urinary tract infection from the University of Benin Teaching Hospital [UBTH]. Isolates were identified based on: Cultural/Morphological characteristics, Gram staining technique and Biochemical testing [5].

\subsection{Susceptibility Testing}

Seven dilutions of the crab shell extract were transferred into prepared Nutrient agar plates containing isolates using the punch-hole agar diffusion method [18] and incubated for 24 hours at $37^{\circ} \mathrm{C}$. The 
$1 \%$ acetic acid was also tested differently to determine if susceptibility would be as a result of the acetic present in the different dilutions.

Known concentrates of commonly used antibiotics were also tested against the clinical isolates

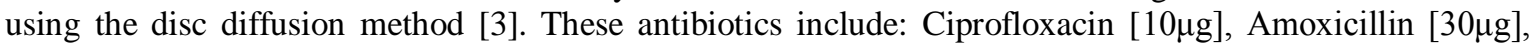

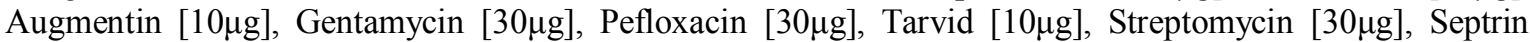
$[30 \mu \mathrm{g}]$, Chloramphenicol $[30 \mu \mathrm{g}]$ and Sparfloxacin $[10 \mu \mathrm{g}]$. After 24 hours of incubation, zones of inhibition were measured and recorded.

\section{CONCLUSIONS}

In conclusion, results from this study has demonstrated the antimicrobial activity of crab shell extract as suggested by a number of researchers $[17 ; 4 ; 7]$. Researchers have also shown that crab shell is biocompatible with human tissues, therefore less toxic than commonly used antibiotics [16; 19]. Thus, instead of the wasteful disposal of crab shells after consuming the fleshy part, more research should be geared towards the effective usage of crab shell extract as an antimicrobial agent. This would serve as an economic advantage to the country.

\section{REFERENCES}

[1] I. Aranaz, M. Mengíbar, R. Harris, I. Paños, B. Miralles, N. Acosta, G. Galed, and A. Heras, Functional characterization of chitin and chitosan, Current Chemical Biology, 3, 2009, 203-230.

[2] M. E. I. Badawy, and E. Rabea., A biopolymer chitosan and its derivatives as promising antimicrobial agents against plant pathogens and their applications in crop protection, International Journal of Carbohydrate Chemistry, 2011, 29pp.

[3] A. W. Bauer, W. M. Kirby, J. C. Sherris, and M. Turck, Antibiotic susceptibility testing by standardized single disk method, American Journal of Clinical Pathology, 45(4) 1966, 493-496.

[4] P. Chhabra, Y. W. Huang, J. F. Frank, R. Chmielewski, and K. Gates, Fate of Staphylococcus aureus, Salmonella enteric, Serovar typhimurium, and Vibrio vulnificus in raw oysters treated with chitosan. Journal of Food Protection, 69, 2006, 16001604.

[5] M. Cheesbrough, District Laboratory Practice in Tropical Countries (Cambridge University Press, Cambridge, U.K., 2000)

[6] G. Emori, and P. Gaynes, An overview of nosocomial infections including the role of the microbiology laboratory, Clinical Microbiology Review, 6(4), 1993, 428-442.

[7] M. Ganan, A. V. Carrascosa, and A. J. Martinez-Rodriguez, Antimicrobial activity of chitosan against Campylobacter spp. and other microorganisms and its mechanism of action, Journal of Food Protection, 72, 2009, 1735-1738.

[8] N. F. A. Gossen, Application of Chitin and Chitosan (Technomic Publishing Company Book, Lancaster, 1997)

[9] S. Hirano, Production and application of chitin and chitosan in Japan, in G. Skjak- Braek, T. Anthonsen \& P. Sandford (Eds.), Chitin and Chitosan: Sources, Chemistry, Biochemistry, Physical Properties and Application (Elsevier Applied Science: London and New York, 1989) 37-44.

[10] V. I. Ibekwe, N. F. Nanyere, and C. O. Akujobi, Studies on antibacterial activity and phytochemical qualities of extracts of orange peels, International Journal of Environmental Health and Human Development, 2(1) 2001, 41-46.

[11] S. Jing, L. Li, Y. Takiguchi, and T. Yamaguchi, Effect of chitosan on renal function in patients with chronic renal failure, Journal of Pharmaceutical Pharmacology, 1997, 49, 721-723.

[12] J. Y. Kim, K. N. Kim, J. G. Kim, S. C. Kim, W. J. Lee1, and Hyun, C. G, In vitro antimicrobial and antioxidant activities of chitosan oligosaccharides, Journal of Applied Biology and Chemistry, 52(2), 2009, 84-87.

[13] D. Knorr, Functional properties of chitin and chitosan, Journal of Food Science, 47, 1982, 593-595.

[14] D. Knorr, Use of chitosan polymer in food: A challenge for food research and development, Food Technology, 38, $1984,85-87$.

[15] S. S. Koide, Chitin - Chitosan: properties, benefits and risks, Nutrition Research, 18(6), 1998, 1091-1101.

[16] H. K. No, S. P. Meyers, W. Prinyawiwatkul, and Z. Xu, Applications of chitosan for improvement of quality and shelf life of foods: a review, Journal of Food Science, 2007, 72, 87-100.

[17] H. K. No, N. Y. Park, S. H. Lee, and S. P. Meyers, Antibacterial activity of chitosans and chitosan oligomers with different molecular weights, International Journal of Food Microbiology, 74, 2000, 65-72. 
[18] A. E. J. Okwori, C. I. Okeke, A. Uzoechina, N. S. Etukudoh, M. N. Amali, J. A. Adetunji, and A. O. Olabode, The antibacterial potentials of Nauclea latifolia. African Journal of Biotechnology, 7(10), 2008, 1394-1399.

[19] D. Raafat, and H. G. Sahl, Chitosan and its antimicrobial potential - a critical literature survey, Microbial Biotechnology, 2, 2009, 186-201.

[20] G. A. F. Roberts, Chitin Chemistry (Macmillan, London, 1992).

[21] R. N. Schiller, E. Barrager, A. G. Schauss, J. R., Veltmann, and E. J. Nicolas, A randomized double-blind placebocontrolled study examining the effects of a rapidly soluble chitosan dietary supplement on weight loss and body composition in over weight and mild obese individual, Journal of the American Nutraceutical Association, 4, 2001, 42-49.

[22] J Sedor, and S. Mulholland, Hospital acquired UTI associated with the indwelling catheter, Urologic Clinics of North America, 26(4), 1999, 821-828.

[23] J. F. Y. Vincent, Insect cuticle: a paradigm for nature composites, in J. F. Y. Incent, J. D. Currey (Eds.), The Mechanical Properties of Biological Materials (Cambridge, The University Press: U.K., 1980) 183- 210. 